\section{Low-Level Atmospheric Ducts}

IN a recent communication in Nature ${ }^{1}$, McPetrie and Starnecki have directed attention to the presence of atmospheric ducts at or close to the sea surface. The presence of low atmospheric ducts when the air at $100 \mathrm{ft}$. above sea-level was colder than the sea was found difficult to explain, and it was noted that such ducts were frequently associated with high wind speeds.

In a recent paper ${ }^{2}$ of limited circulation dealing with observations in Cardigan Bay, I have shown that the mean specific humidity, $s$, of the air in the layer between 200 and $2,000 \mathrm{ft}$. above the sea, after an uninterrupted sea track, is related to the saturation specific humidities at the sea surface temperatures during the previous 48 hours history of the air by an expression of the form

$$
s=0.34\left(s_{1}+s_{2}\right),
$$

where $s_{1}$ is the saturation specific humidity at the sea surface temperature at the place of observation, and $s_{2}$ that for the sea surface temperature at the place where the air was 48 hours before. Thus the lower the value of $s_{2}\left(s_{1}\right.$ varies only slowly with time and is sensibly constant over a period of days at a particular place in Cardigan Bay) the lower the value of $s$, and hence the greater the value of the humidity lapse in the lowest layers of the air. In the same paper $^{2}$, it is suggested that much the greater part of this humidity lapse frequently occurs in the lowest few feet of the air. If the air under examination comes from an area where the sea surface temperatures are much lower than in Cardigan Bay, then the stronger the wind the colder the sea surface temperature at the place the air was 48 hours before, and the greater the value of the humidity lapse in the Cardigan Bay area. The occurrence of low-level radio ducts in conditions of high winds when the air temperature is substantially less than the sea surface temperature can therefore be explained on this basis alone. The occurrence of ducts when the air temperature at $100 \mathrm{ft}$. was substantially above the sea temperature can almost certainly be explained by the presence of air which had recently come from the warmer and drier land, with the consequent presence of both temperature inversion and humidity lapse in the lowest layers, leading to even stronger ducts than those considered above. It is extremely unlikely that temperature inversions of such magnitude accompanied by a marked humidity lapse could occur over the sea, except in the neighbourhood of a warmer land mass.

I am indebted to the Director of the Meteorological Office for permission to submit this note.

Meteorological Office,

$$
\text { R. F. JONES }
$$
East Hill,

Nr. Dunstable, Beds. Nov. 30 .

${ }^{1}$ Nature, 162, 818 (1948).

'Jones, R. F., "Temperature and Humidity Structure of Lowest Layers of the Air over the Sea", Air Ministry, J.M.R.P. No. 92 (1947).

We are grateful to Mr. Jones for outlining his suggestion as to a possible method for the formation of the low-level atmospheric ducts in Cardigan Bay which we postulate from our radio field-strength measurements. According to current radio-meteorological theory, ducts should not occur during turbu- lent conditions. It surprised us, therefore, to find from the radio measurements that in the winter high field-strengths, which suggest to us the presence of low-level ducts, could occur even during windy weather. Mr. Jones's hypothesis gives a very satisfactory quantitative explanation of a method by which ducts might be formed during such periods of high wind velocity. High field-strengths during winter, however, appeared to depend more on the fact that the temperature of the air was appreciably lower than that of the sea, rather than on the presence or absence of wind. The main difference between windy and still conditions was not in the amplitude of the received signal but in its stability, remarkably little fading ever being found during windy periods.

Sverdrup, in his book "Oceanography for Meteorologists", arrives at the conclusion that the greatest evaporation occurs when cold air flows over warm water; as in middle and higher latitudes in winter the sea surface is mostly warmer than the air, evaporation should be a maximum in winter and not summer, as generally supposed. Sverdrup's results, while only qualitative, seem to us to account satisfactorily for the possibility of ducts occurring during still air conditions in winter. Sverdrup also concludes that the evaporation should be increased at higher wind velocities because of the presence of spray-a hypothesis which we tentatively suggested in our note to explain the presence of ducts during windy conditions.

Signals Research and

J. S. MCPETRIE

B. STARNECK]

Development Establishment, (Ministry of Supply), Christchurch.

\section{Preparation of Radioautographs to Show the Distribution of Phosphorus-32 in Plant Tissues}

PeLC ${ }^{1}$ has developed a radioautographic technique to show in microscopic detail the accumulation of iodine-131 in the thyroid gland. A thin 'stripping' photographic emulsion is floated on to the tissue sections mounted on a glass slide. The precision with which the tracer can be located within the tissue depends not only on the thinness of the section and the emulsion but also on the closeness of contact between them. In applying this method to the study of the distribution of phosphorus in plant tissues the following complications arise: (1) a considerable diffusion of phosphorus occurs in the fixatives norm. ally used; (2) the time required to prepare sections by standard plant histological methods is so long that much of the tracer decays before the radioautograph can be exposed.

We have found that these difficulties can be largely overcome by employing a 'freezing substitution' technique which one of us (F. K. S.) is developing for other purposes, and following this by a rapid im. bedding method. The time required for preparing sections of material such as cereal root tips has thereby been reduced to twenty-four hours.

The tissue is frozen in isopentane chilled to about - $170^{\circ} \mathrm{C}$. and then transferred to absolute alcohol saturated with basic lead acetate, which is maintained at $-70^{\circ} \mathrm{C}$. in a jacket of 'dry ice' alcohol. The ice in the tissue dissolves slowly in the cold alcohol 